\title{
q-LAMP Assays for the Detection of Botryosphaeria dothidea Causing Chinese Hickory Canker in Trunk, Water, and Air Samples
}

\author{
Q. W. Wang and C. Q. Zhang ${ }^{\dagger}$ \\ College of Agriculture and Food Science, Zhejiang A \& F University, Lin'an, Zhejiang 311300, People's Republic of China
}

\begin{abstract}
Trunk canker disease caused by Botryosphaeria dothidea with a prolonged latent infection phase poses a serious threat to Chinese hickory production. To further understand the epidemiological characteristics and develop reasonable management techniques, a quantitative loopmediated isothermal amplification (q-LAMP) assay was developed to quantitatively monitor $B$. dothidea in hickory plants, water, and air samples. Specific primers were designed based on the different sites of the $\beta$-tubulin sequence between $B$. dothidea and other fungi commonly

specifically distinguish $B$. dothidea from other tested fungi. The limit of detection of LAMP assays for $B$. dothidea was $0.001 \mathrm{ng} / \mu$ l of pure genomic DNA and 10 spores per $1 \mathrm{ml}$ of water. The q-LAMP assay enables rapid detection of $B$. dothidea within 60 min in hickory trunk, water in hickory forests, and spores captured on tapes. These results provide a powerful and convenient tool for monitoring $B$. dothidea, which could be applied widely in epidemiology, forecast, and management of tree canker disease.
\end{abstract} found on Chinese hickory. At the optimum reaction temperature of $65.9^{\circ} \mathrm{C}$, this loop-mediated isothermal amplification (LAMP) assay can
Keywords: pathogen detection, tree nuts
Chinese hickory (Carya cathayensis Sarg), a deciduous tree of Juglandaceae, is a well-known fruit and woody oil tree species native to China. This species has a distinctive fragrance and high nutritional value, and it is mainly distributed in the Tianmu Mountain area and Changbei District at the junction of Zhejiang and Anhui provinces in China (Ma et al. 2009; Wang 2004; Zhu et al. 2008). At present, there are about 1,300,000 ha of Chinese hickory cultivated in China, with an average annual output value of $\$ 260$ million and a processing output value of $\$ 509$ million (Zhang et al. 2018). The widespread outbreak of canker disease caused by Botryosphaeria dothidea seriously threatens the sustainable development of the Chinese hickory industry (Yunwei et al. 2015; Zhang and Xu 2011; Zhang et al. 2015). B. dothidea, one of the most common fungal pathogens damaging trees worldwide, infects the hosts through wounds, and it breaches the outer bark and colonizes the phloem, vascular cambium, and xylem. This blockage causes a weakening and decay of the wood at the infection sites (Slippers et al. 2007). This pathogenic fungus can easily be missed during the management time point or simply pass undetected by quarantine systems because of its prolonged latent infection or endophytic phase (Marsberg et al. 2017). Canker symptoms generally occur on trunks of hickory below $\sim 200 \mathrm{~cm}$, and few lesions are observed on other parts, such as twigs, branches, and nuts. The occurrence period of trunk canker is from late March to late November annually, and the pathogen overwinters around the diseased tissues with obvious latent infection characteristics (Dai et al. 2017; Yang et al. 2009). The B. dothidea fungus exists in hickory trees all year round, and the obvious canker symptoms will not be observed until April when is too late to start treatment of the disease. At present, this disease is observed by the naked eye, and thus, a big gap exists in the preliminary prediction of this disease.

${ }^{\dagger}$ Corresponding author: C. Q. Zhang; cqzhang@ zafu.edu.cn

Funding: This study is supported by Key Important Research Project of Hangzhou grant 20172015A01.

*The $\boldsymbol{e}$-Xtra logo stands for "electronic extra" and indicates that three supplementary figures are published online.

The author(s) declare no conflict of interest.

Accepted for publication 29 May 2019.

(C) 2019 The American Phytopathological Society
Previous studies conducted in California pistachio orchards have confirmed $B$. dothidea to be a water splash-dispersed pathogen with relatively short distances of spore dispersal (Ahimera et al. 2004; Michailides 1993). Under moist conditions, pycnidia of Botryosphaeria spp. produce pycnidiospores that are generally exuded in a gelatinous matrix forming cirrhi, a ribbonlike mass of spores (Ahimera et al. 2004; Michailides 1993; Phillips 2002; Úrbez-Torres et al. 2006). In addition, there is still a lack of research on the role of wind in the dissemination of $B$. dothidea conidia. Our previous research indicated that the time of the first fungicide spray, which should be carried out before the initial spore dispersal, greatly impacts efficacy. Additionally, we speculated that $B$. dothidea overwintered on cankers on trunks with obvious latent infection (Dai et al. 2017). However, little is known about the epidemiology and inoculum dispersal of $B$. dothidea infecting Chinese hickory, and the transmission routes of $B$. dothidea among hickory forests and the characteristics of infection in the trunk are still vague. Furthermore, the hickory forest is a complex and open ecological environment. To explore the transmission characteristics of $B$. dothidea, it is very important to quantitatively detect trunk canker fungi on trunks and detect a small number of conidia in water and air between hickory forests. The use of traditional microscopic counting after capturing spores in the forest requires professional classification by technicians, and a long time is required to observe and identify the spores. In view of the complexity of environmental samples and human subjectivity, microscopic counting does not always provide reliable data. A real-time PCR technique was developed and adapted to help quantify canker control by measuring the abundance of the pathogen (Zhu et al. 2016). However, traditional PCR technology is more frequently used for qualitative detection of pathogens, and it is susceptible to interference from PCR inhibitors, dust, and other pathogens in the environment. It is difficult to quantitatively detect low concentrations of captured spores. A new time-saving, low-cost, highly specific, and sensitive nucleic acid amplification method, loop-mediated isothermal amplification (LAMP), has been gradually used (Chotiwan et al. 2017). The results of LAMP can be judged by either turbidity or end products that can be visible to the naked eye with fluorescent reagents, such as SYBR Green I (Tomito et al. 2008), within 60 min under the condition of a constant temperature. The purpose of this study was to establish a quantitative loop-mediated isothermal amplification (q-LAMP) detection technique for the detection of trunk canker fungus in hickory; quantitatively determine the abundance of this fungus in trees, air, and water accurately and quickly; and monitor the change in the content of the fungus so as to provide guidance for the prediction and management of trunk canker fungus in hickory. 


\section{Materials and Methods}

Fungal isolates. Isolates of $B$. dothidea and commonly isolated endophytic fungi of hickory plants sampled from C. cathayensis in Lin'an District, Hangzhou, China are listed in Table 1. Isolates were maintained on potato dextrose agar (PDA) slants at $4^{\circ} \mathrm{C}$.

DNA extraction from mycelium, trunk, and spores. Mycelial DNA was extracted using a Rapid Fungi Genomic DNA Isolation Kit (Sangon Biotech) according to the manufacturer's protocol. DNA from the trunk and conidia was extracted by a Plant Genomic DNA Kit (TIANGEN BIOTECH) according to the manufacturer's protocol. For DNA isolation from diseased trunk tissues, $3 \mathrm{~g}$ of phloem lesions were collected and put into an FW100 highrotation speed disintegrator (Taisite). After $2 \mathrm{~min}$ of crushing, $400 \mathrm{mg}$ of tissues were added with liquid nitrogen to grind the sample with a pestle. Although a small amount of liquid nitrogen remained, the samples were rapidly ground, and this procedure was repeated three to four times. For DNA extraction from conidia, $B$. dothidea were cultured on PDA medium at $25^{\circ} \mathrm{C}$ for 3 days in darkness and then, under a 12-h light/dark condition; a certain number of pycnidia were selected, placed in a centrifuge tube with $1.5 \mathrm{ml}$ of sterile water, and filtered using a $125-\mu \mathrm{m}$ sieve. Suspensions were centrifuged for 5 min at 6,800 rpm using a Sorvall Legend MicroCL 17R Centrifuge (Thermo Scientific). Then, $80 \%$ of the volume was drained, and the pellet was resuspended in the remaining $20 \%$ sample volume by vortexing (Gehesquière et al. 2013). The samples were transferred to a fresh tube and thoroughly mixed with $200 \mathrm{ml}$ of $10 \%$ Chelex-100 solution (Jiliang et al. 2011), $200 \mathrm{ml}$ of $10 \%$ sodium dodecylsulfate (SDS) solution, and $0.4 \mathrm{~g}$ of acid-washed glass beads (Aladdin). This mixture was treated at speed 6.0 for $40 \mathrm{~s}$ by the FastPrep-24 Instrument (MP Biomedicals), and it was then heated in a water bath at $100^{\circ} \mathrm{C}$ for $5 \mathrm{~min}$; the oscillation heating steps were repeated three times followed by refrigeration at $-20^{\circ} \mathrm{C}$ for $2 \mathrm{~min}$. Each sample was centrifuged for $5 \mathrm{~min}$ at 10,000 rpm, and DNA was extracted from the supernatants using a Plant Genomic DNA Kit following the manufacturer's instructions. DNA concentrations were determined spectrophotometrically, and the extracted DNA was stored at $-20^{\circ} \mathrm{C}$ for use in PCR and q-LAMP analyses.

Amplification and analysis of the $\beta$-tubulin sequence of $B$. dothidea from Chinese hickory. The $\beta$-tubulin gene of $B$. dothidea was PCR amplified using the primers T1-5'-AACATGCGTGAGA TTGTAAGT- $3^{\prime}$ and Bt2b-5'-ACCCTCAGTGTAGTGACCCTTGGC$3^{\prime}$ (Lisboa et al. 2016). The reactions contained the following reagents: $12.5 \mu \mathrm{l}$ of $2 \times$ Taq Master Mix, $1 \mu$ l of primers of T1 and Bt $2 b-5^{\prime}, 1 \mu$ of DNA sample, and double-distilled water $\left(\mathrm{ddH}_{2} \mathrm{O}\right)$ to adjust the volume to $25 \mu \mathrm{l}$. The thermal cycling of the PCR program was $94^{\circ} \mathrm{C}$ for $5 \mathrm{~min}$ and 35 reaction cycles of $94^{\circ} \mathrm{C}$ for $30 \mathrm{~s}$, $55^{\circ} \mathrm{C}$ for $30 \mathrm{~s}$, and $72^{\circ} \mathrm{C}$ for $40 \mathrm{~s}$, with an extension at $72^{\circ} \mathrm{C}$ for $5 \mathrm{~min}$. The PCR products were separated by $1 \%$ agarose gel electrophoresis, and genomic DNA was purified using a SanPrep Column DNA Gel Extraction Kit (Sangon). The purified PCR products were sequenced by GenScript. The sequence analysis and homology blasts were conducted.

Sequences of $\beta$-tubulin for Botryosphaeria corticis (GenBank accession no. EU673107), Botryosphaeria eucalyptorum (GenBank accession no. AY236920), Botryosphaeria fabicerciana (GenBank accession no. KF779068), Botryosphaeria lutea (GenBank accession no. AY236923), Botryosphaeria parva (GenBank accession no. AY236912), Botryosphaeria rosaceae (GenBank accession no. KX197101), Pestalotiopsis microspora (GenBank accession no. KU377338.1), Trichoderma viride (GenBank accession no. Z15055.1), Fusarium proliferatum (GenBank accession no. KJ544178.1), Nigrospora chinensis (GenBank accession no. KY019579.1), and Daldinia sp. (GenBank accession no. KU684130.1) were downloaded from GenBank to compare the differences in the amplified $\beta$-tubulin sequences between $B$. dothidea from Chinese hickory and other fungi.

LAMP primer design and screening. According to the difference in the $\beta$-tubulin area, four sets of LAMP primers were designed using Primer explorer V5 software (http://primerexplorer.jp/e/). The LAMP assay was performed in $25-\mu l$ reaction mixtures, including a final concentration of $4.8 \mathrm{U}$ Bst DNA polymerase (New England Biolabs), $2.5 \mu \mathrm{l}$ of $10 \times$ TermoPol buffer, $1 \mathrm{mM}$ dNTPs, $5 \mathrm{mM}$ $\mathrm{Mg}^{2+}, 1.6 \mu \mathrm{M}$ FIP and BIP, $0.2 \mu \mathrm{M}$ F3 and B3, 0.6 M betaine, $150 \mu \mathrm{M}$ hydroxynaphthol blue (HNB; metal ion indicator), and $1 \mu \mathrm{l}$ of DNA sample $(100 \mathrm{ng} / \mu \mathrm{l})$. The volume was adjusted to $25 \mu \mathrm{l}$ with nucleic acid-free water. The LAMP reactions were incubated at $65.9^{\circ} \mathrm{C}$ for $60 \mathrm{~min}$, and each process was repeated at least three times. Thereafter, the best set of primers screened that showed the most intensive sky blue color was used for the q-LAMP assay performed later.

q-LAMP reaction mixtures. The q-LAMP assay was performed in a $20-\mu l$ reaction mixture, including a final concentration of $8 \mathrm{U}$ Bst DNA polymerase (New England Biolabs), $2 \mu 1$ of $10 \times$ TermoPol buffer, $1 \mathrm{mM}$ dNTPs, $6.25 \mathrm{mM} \mathrm{Mg}{ }^{2+}, 1.6 \mathrm{M}$ FIP and BIP, $0.125 \mu \mathrm{M} \mathrm{F} 3$ and B3, 0.6 M betaine, $1.2 \mu \mathrm{l}$ of $10 \times$ SYBR Green I (TaKaRa), and $1 \mu \mathrm{l}$ of DNA sample ( 0.001 to $100 \mathrm{ng} / \mu \mathrm{l})$. The volume was adjusted to $20 \mu \mathrm{l}$ with nucleic acid-free $\mathrm{ddH}_{2} \mathrm{O}$. The LAMP reactions were incubated at $65.9^{\circ} \mathrm{C}$ for $60 \mathrm{~min}$ and performed using a CFX96 thermocycler (BioRad).

Determination of optimum reaction temperature for the q-LAMP assay. To better facilitate the reaction, a series of constant temperatures was set up (e.g., 67.0, 66.6, 65.9, 64.5, 62.8, 61.4, 60.5, and $60.0^{\circ} \mathrm{C}$ ). The screening results can be determined based on fluorescence intensity and reaction time.

Verification of the specificity of the q-LAMP assay. Each q-LAMP series consisted of three replicate reactions containing DNA (at a concentration of $0.1 \mathrm{ng} / \mu \mathrm{l}$ ) of the $B$. dothidea and non$B$. dothidea strains listed in Table 1 . The reaction was treated at the selected optimum temperature.

Establishment of a DNA standard curve for mycelium and spore samples. Mycelial DNA samples were 10-fold diluted in water and used as templates for the q-LAMP assay. The final concentrations of DNA were 100, 10, 1, 0.1, 0.01, and $0.001 \mathrm{ng} / \mu 1$. DNA of mycelia and six 10 -fold dilution series of conidia $\left(1.0 \times 10^{5} / \mathrm{ml}\right.$ to $\left.1.0 \times 10 \% \mathrm{ml}\right)$ were placed into the instrument and allowed to react. No-template control reactions were included in which the DNA was substituted with nucleic acid-free water. For quantification, two standard curves for pure DNA from mycelia and conidia were constructed separately by analyzing the association of logarithmic values of the initial template concentration and cycle threshold $(\mathrm{Ct})$ values.

Detection of $B$. dothidea in the trunk by q-LAMP assays. In the woods of Taiyang Town, Lin'an District, Hangzhou City, the phloem tissues of hickory trees were collected at intervals of 0 , 5,10 , and $20 \mathrm{~cm}$ from a targeted canker lesion. During 2018, tissues from a total of 100 targeted canker lesions of different trees were collected from Taiyang Town. The absolute quantitative method was used to react the sample with a standard sample simultaneously using a CFX96 thermocycler. Extraction of DNA from samples was done using the methods described earlier. The cycle threshold values of the sample and the standard sample were recorded. The standard curve obtained by diluting the standard sample was used to determine the amount of DNA of B. dothidea in the sample.

Table 1. Isolates of Botryosphaeria dothidea and commonly isolated endophytic fungi isolates of hickory plants used in this study

\begin{tabular}{|c|c|c|c|}
\hline Species & $\begin{array}{l}\text { Isolate } \\
\text { no. }\end{array}$ & Source & Year \\
\hline B. dothidea & BD16-1 & Lin'an District, Hangzhou, China & 2016 \\
\hline B. dothidea & BD17-1 & Lin'an District, Hangzhou, China & 2017 \\
\hline B. dothidea & BD18-1 & Lin'an District, Hangzhou, China & 2018 \\
\hline $\begin{array}{l}\text { Pestalotiopsis } \\
\text { microspora }\end{array}$ & PM18-1 & Lin'an District, Hangzhou, China & 2018 \\
\hline Trichoderma viride & TV18-1 & Lin'an District, Hangzhou, China & 2018 \\
\hline $\begin{array}{l}\text { Fusarium } \\
\text { proliferatum }\end{array}$ & FP18-1 & Lin'an District, Hangzhou, China & 2018 \\
\hline Nigrospora chinensis & NC18-1 & Lin'an District, Hangzhou, China & 2018 \\
\hline $\begin{array}{l}\text { Alternaria } \\
\text { oregonensis }\end{array}$ & AO18-1 & Lin'an District, Hangzhou, China & 2018 \\
\hline Daldinia sp. & DS18-1 & Lin'an District, Hangzhou, China & 2018 \\
\hline
\end{tabular}


Monitoring B. dothidea conidia from artificial and natural water samples by q-LAMP assays. Three independent dilution series of 10-ml samples were established in 50-ml conical flasks using rainwater and $100 \mathrm{mg}$ of field soil collected in the hickory forests and containing $1,000,100,10$, or 0 conidia. These samples were concentrated to 1-ml volumes to extract DNA using the methods mentioned above. The DNA samples were submitted to q-LAMP analysis using the optimized thermocycling conditions.

In the forests infected with $B$. dothidea, five open metal containers $(30 \times 20 \times 10 \mathrm{~cm})$ were randomly placed at a distance of $50 \mathrm{~cm}$ from a symptomatic trunk (Gehesquière et al. 2013). The containers were placed before a predicted period of rainfall, and rainwater in each container was collected the next day. Using the centrifugal scheme mentioned above, $100-\mathrm{ml}$ water samples collected in each container were concentrated to $1 \mathrm{ml}$, and then, the same method was used to extract the DNA of the conidia. The DNA samples were submitted to q-LAMP analysis.1

Monitoring $B$. dothidea conidia from artificial and natural air samples by q-LAMP. The spores of $B$. dothidea were added to Melinex tapes $(2 \times 2 \mathrm{~cm})$ on a clean bench, and the numbers of spores were $1,000,100$, and 10 per tape. The tapes with spores were cut and placed in a 2-ml centrifuge tube, and the conidial DNA was extracted according to the methods mentioned above. The DNA samples were submitted to q-LAMP analysis, and the amplification time was recorded. According to the established standard curve for conidia, the number of spores was calculated and compared with the number of spores added artificially to evaluate the accuracy of the q-LAMP detection results.

An airborne spore catcher (Jiaduo) containing Melinex tapes was set up in a C. cathayensis forest in Taiyang Town, Lin'an District, Hangzhou City. Beginning on 13 May 2018, samples were collected every 7 days five consecutive times. The DNA of conidia was extracted and submitted to q-LAMP analysis. The number of spores on the tape was calculated based on the results of the q-LAMP reaction.

\section{Results}

Primer design and validation. Four sets of primers (Table 2) were designed for LAMP detection of $B$. dothidea based on the different sites of the $\beta$-tubulin sequence between the $B$. dothidea isolates and other fungi (Fig. 1). The experimental results show that primer group A has excellent sensitivity and high efficiency (not shown in detail).

Optimum reaction temperature for the q-LAMP assay. The fluorescence quantitative results showed that the strongest fluorescence intensity and the shortest reaction time were obtained when the reaction temperature was $65.9^{\circ} \mathrm{C}$ (Supplementary Fig. S1). Thus, $65.9^{\circ} \mathrm{C}$ was adopted as the reaction temperature to carry out the q-LAMP assays.

Specificity verification of the q-LAMP assay. At the optimum reaction temperature of $65.9^{\circ} \mathrm{C}$, the reference strains were validated by LAMP with the screened primer group A. The color of the positive amplifications in $B$. dothidea LAMP tubes changed from violet to blue when detected with HNB reagents, whereas the color remained violet in the other fungi and the blank tube with 1-h reaction periods (Fig. 2A). The LAMP products were separated by $1 \%$ agarose gel electrophoresis; ladder-liker patterns were observed in the positive reactions but not in negative controls (Fig. 2B). In addition, the specificity of primer group A also was verified by q-LAMP assay. Fluorescence signals were detected in DNA samples containing $B$. dothidea, but no fluorescence signals were detected in the other six fungal DNA and control samples (Fig. 2C).

Establishment of a DNA standard curve for mycelium DNA and spores. Serial dilutions $(100,10,1,0.1,0.01$, and $0.001 \mathrm{ng} /$ $\mu l)$ of the mycelial genomic DNA of $B$. dothidea were used as templates to determine the analytical sensitivity of the LAMP assays. The amplification times of each concentration were 16.32, 18.68, $22.43,26.63,30.84$, and $33.26 \mathrm{~min}$, respectively. The limit of detection (LOD) of LAMP assays for independently detecting $B$. dothidea DNA from mycelia was $0.001 \mathrm{ng} / \mu \mathrm{l}$ (Fig. 3A). Defining $\log$ (DNA concentration value/0.0001) as the $x$ axis and the corresponding CT value as the $y$ axis, a standard curve was constructed; that is:

$$
y=-3.5823 x+37.233
$$

(Fig. 3B), the DNA concentration calculation formula is:

$$
10^{\left(\frac{37.233-y}{3.5823}-4\right)}
$$

and the correlation coefficient $R^{2}=0.9904$, which showed a good linear relationship.

The serial dilutions $\left(10^{5}, 10^{4}, 10^{3}, 10^{2}\right.$, and $10^{1}$ spores per milliliter $)$ of the genomic DNA of spores were used as templates to determine the analytical sensitivity of LAMP assays. The amplification times of each concentration were $16.67,21.51,28.69,36.26$, and $43.61 \mathrm{~min}$, respectively. The LOD for detecting $B$. dothidea spores was 10 spores per milliliter (Fig. 3C). The standard curve was established based on the association of logarithmic values $(x)$ of the number of spores per milliliter and cycle threshold values $(y)$ :

\begin{tabular}{|c|c|c|}
\hline $\begin{array}{l}\text { Primer set name and } \\
\text { primer name }\end{array}$ & Type & Sequence $\left(5^{\prime}\right.$ to $\left.3^{\prime}\right)$ \\
\hline \multicolumn{3}{|l|}{ A } \\
\hline F3-1 & Forward outer & TGTCCATAGGTTCACCTCCA \\
\hline B3-1 & Reverse outer & AGATGGTCTGCCTGTGGT \\
\hline FIP-1 & Forward inner & CAAAGTCAGCGCGATGCAGCGACCGGCCAATGCGTAAG \\
\hline BIP-1 & Reverse inner & AGGGTAACCAAATCGGTGCTGCGTCGATTCGCGTTAGCGG \\
\hline \multicolumn{3}{|r|}{ 皮 } \\
\hline $\mathrm{F} 3-2$ & Forward outer & CCTCCCGACCATCTTTTTCG \\
\hline B3-2 & Reverse outer & TGTTCTCCCACGCTGAGA \\
\hline FIP-2 & Forward inner & CGGGTGTTTTGGCAACAAACCATGCATCGCGCTGACTTTG \\
\hline BIP-2 & Reverse inner & CCGCTAACGCGAATCGACACCGACTTACACGCCAGAGCC \\
\hline \multicolumn{3}{|r|}{ (2) } \\
\hline F3-3 & Forward outer & CGGCCAATGCGTAAGTCTC \\
\hline B3-3 & Reverse outer & GACTTACACGCCAGAGCC \\
\hline FIP-3 & Forward inner & GCAGCACCGATTTGGTTACCCTCTCCCGACCATCTTTTTCGC \\
\hline BIP-3 & Reverse inner & TGGTTTGTTGCCAAAACACCCGCGGAGATGGTCTGCCTGT \\
\hline \multicolumn{3}{|r|}{ 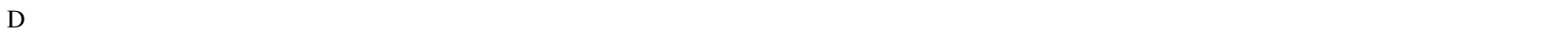 } \\
\hline F3-4 & Forward outer & TCCATAGGTTCACCTCCAGA \\
\hline B3-4 & Reverse outer & GACTTACACGCCAGAGCC \\
\hline FIP-4 & Forward inner & GCAGCACCGATTTGGTTACCCTGCGTAAGTCTCCTCCCGA \\
\hline BIP-4 & Reverse inner & TGGTTTGTTGCCAAAACACCCGCGGAGATGGTCTGCCTGT \\
\hline
\end{tabular}

Table 2. The sequences of the loop-mediated isothermal amplification primers used in this study 


$$
Y=-6.863 x+49.937
$$

(Fig. 3D); the calculation used to determine the number of spores is:

$$
10^{\left(\frac{49.937-y}{6.863}\right)}
$$

and the correlation coefficient $R^{2}=0.9922$, which showed a good linear relationship.

Application of q-LAMP assays detecting $B$. dothidea from trunks. For the samples collected from the infected trunks in Taiyang Town (TY-0, TY-5, TY-10, and TY-20) (Fig. 4A and B), the q-LAMP assay results showed that the amplification times of trunk samples were 23.99, 26.41, 31.54, and $33.82 \mathrm{~min}$ (Fig. 4C). According to the DNA concentration calculation formula;

$$
10^{\left(\frac{37.233-y}{3.5823}-4\right)}
$$

the DNA concentration values corresponding to each sample were $0.498,0.105,0.004$, and $0.001 \mathrm{ng} / \mu \mathrm{l}$, respectively. Therefore, there is a phenomenon in which DNA of B. dothidea was detected from asymptomatic trunk tissues, and the amount of DNA of $B$. dothidea decreases as the distance from the lesion increases.

Application of q-LAMP assays detecting $B$. dothidea in water. Using the established q-LAMP detection system, it was found that the amplification times of spore samples added quantitatively to artificially prepared water samples were $29.31,36.40$, and 43.54 min. According to the calculation formula:

$$
10^{\left(\frac{49.937-y}{6.863}\right)}
$$

the numbers of spores corresponding to each sample were 1,012.83, 93.86, and 8.55, respectively. The q-LAMP detection results of spore number were consistent with those of artificial additions (Fig. 5).

Moreover, it was found that the amplification times of spore samples in forest water samples were 30.93, 33.22, 34.00, 37.45, and 39.09 min (Supplementary Fig. S2). According to the calculation formula:
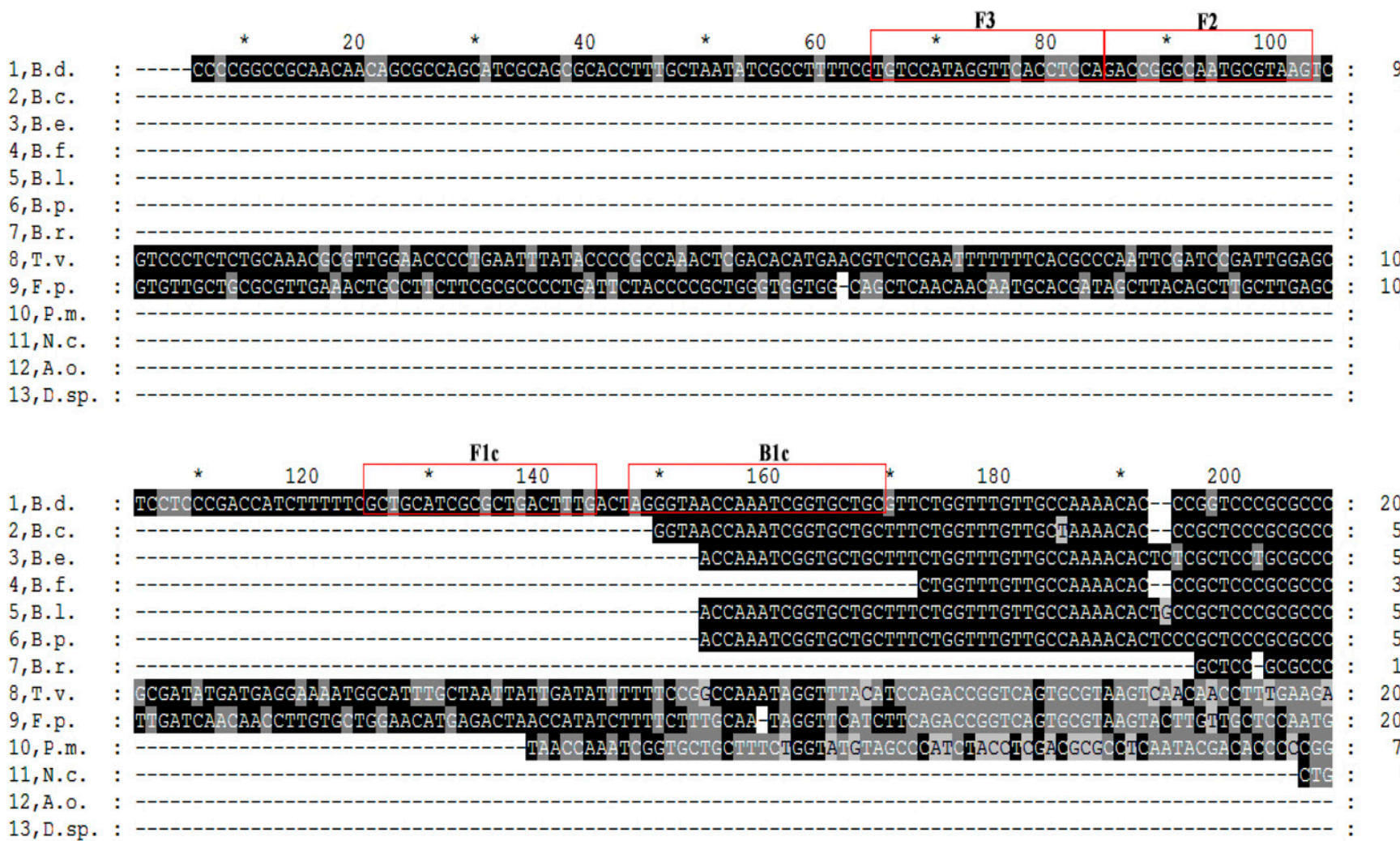

4, B.f.

5, B. 1 .

$6, \mathrm{~B} \cdot \mathrm{p}$

9, F.p.

10, P.m

13, D.sp.

B3

1,B.d.
2,B.c.
3, B.e.
4, B.f.
5, B.1.
6, B.p.
7, B.r.
8, T.v.
9, F.p.
10, P.m.
11, N.c.
12,A.o.
13, D.sp.
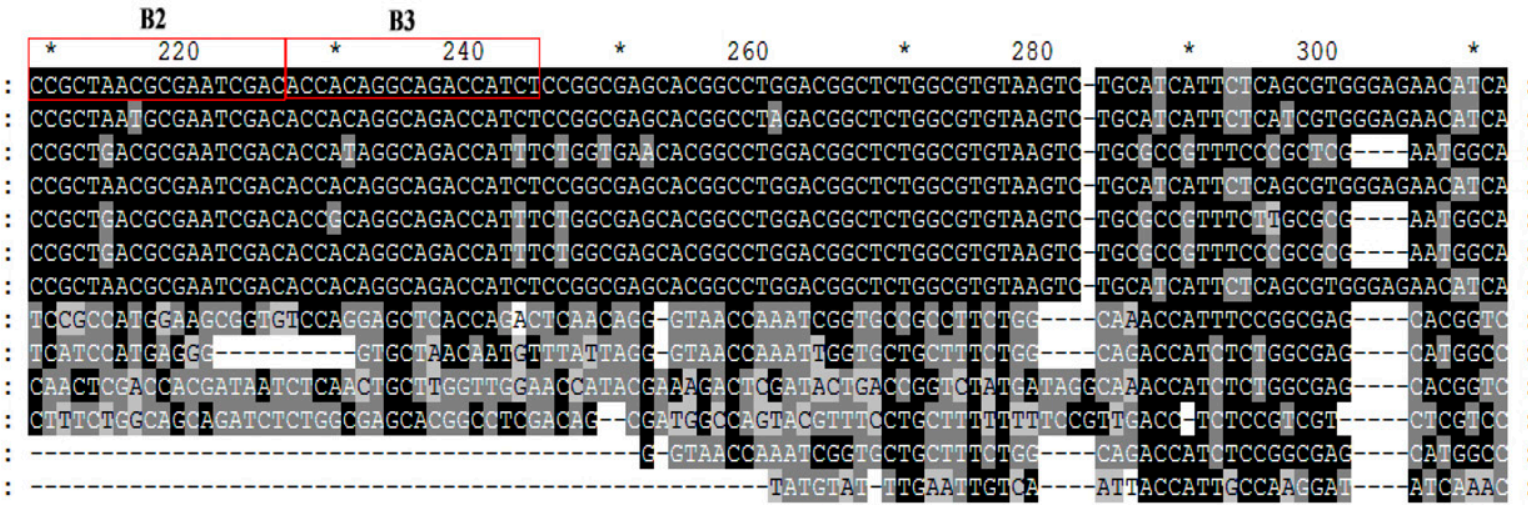

Fig. 1. Sequence and location of the $\beta$-tubulin gene segments in Botryosphaeria dothidea used to design loop-mediated isothermal amplification (LAMP) primers. Primer locations for LAMP assays (F3, B3, FIP [F1c to F2], and BIP [B1C to B2]). FIP is a hybrid primer consisting of the F1c and F2 sequences; BIP is a hybrid primer consisting of the B1C and B2 sequences. Primer sequence sites are red and marked. 1: B. dothidea; 2: Botryosphaeria corticis; 3: Botryosphaeria eucalyptorum; 4: Botryosphaeria fabicerciana; 5: Botryosphaeria lutea; 6: Botryosphaeria parvas; 7: Botryosphaeria rosaceae; 8: Trichoderma viride; 9: Fusarium proliferatum; 10: Pestalotiopsis microspora; 11: Nigrospora chinensis; 12: Alternaria oregonensis; and 13: Daldinia sp. 

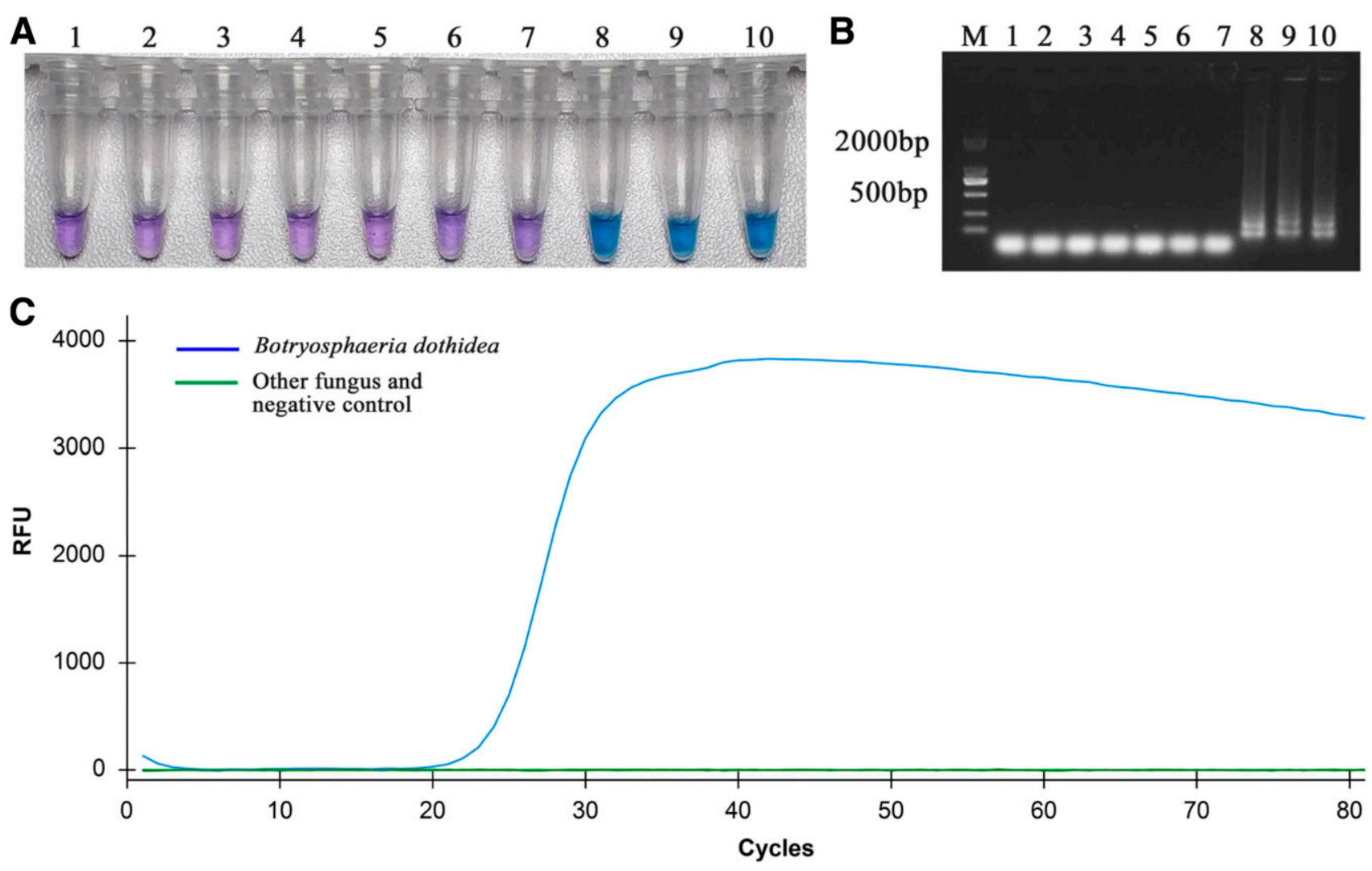

Fig. 2. Specificity of the quantitative loop-mediated isothermal amplification detection system for Botryosphaeria dothidea, $\mathbf{A}$, on the basis of $\mathrm{HNB}$ color change; $\mathbf{B}$, on the basis of gel electrophoresis, lane 1: Trichoderma viride; 2: Fusarium proliferatum; 3: Pestalotiopsis microspora; 4: Nigrospora chinensis; 5: Alternaria oregonensis; 6: Daldinia sp. 7: CK; 8: BD16-1; 9: BD17-1; 10: BD18-1; M: DNA marker. C, Fluorescence signals detected in DNA samples containing $B$. dothidea. RFU: relative fluorescence units.
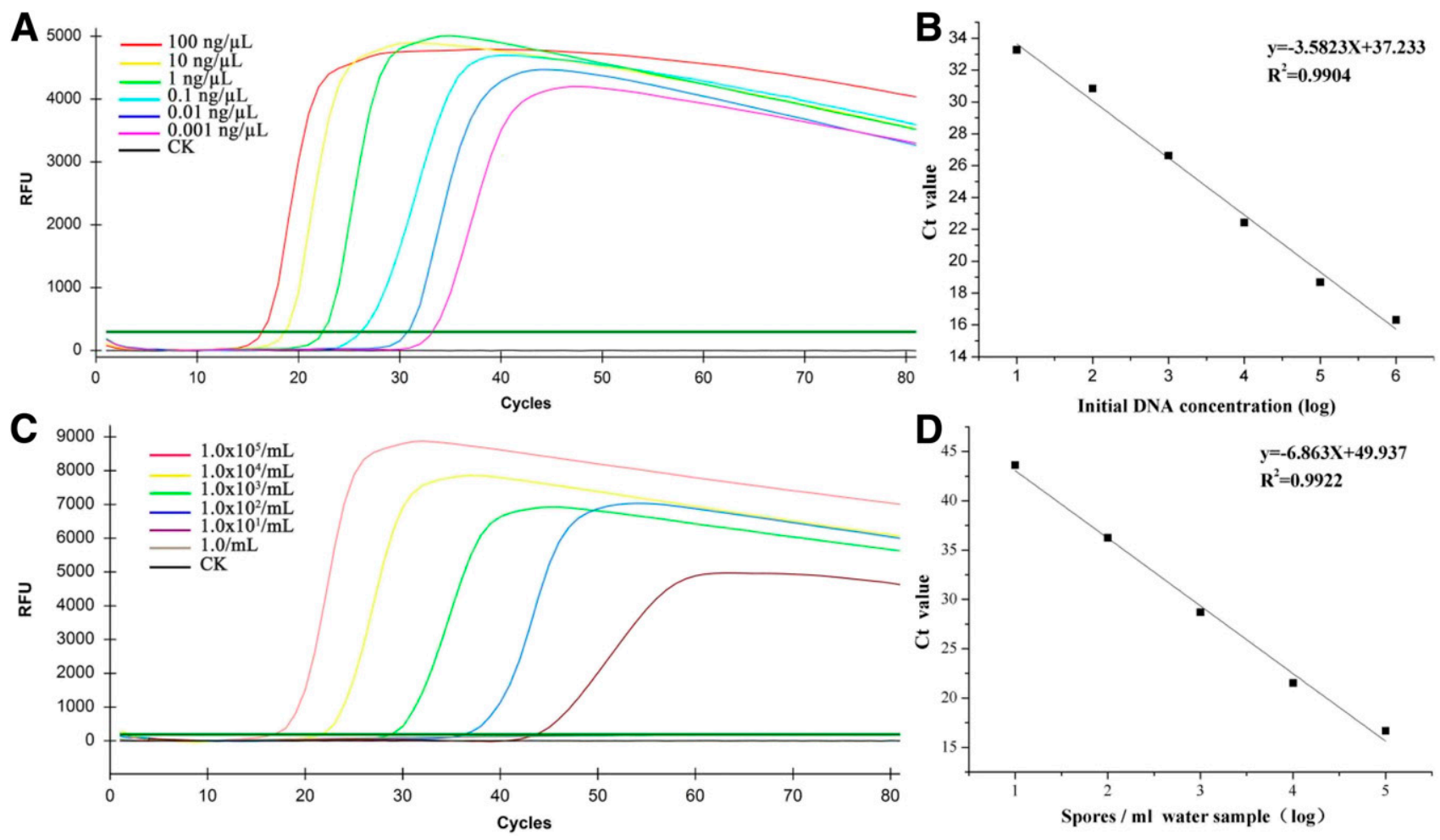

Fig. 3. Standard curve of mycelium DNA and spore for Botryosphaeria dothidea. A, A representative amplification plot for 10-fold serial dilution containing $100 \mathrm{ng}$ to $0.001 \mathrm{ng}$ of DNA. B, Standard curve derived from absolute quantification of 10-fold serially diluted DNA from mycelium of $B$. dothidea. C, A representative amplification plot for 10-fold serial dilution containing $10^{5}$ to $1 \mathrm{spores} / \mathrm{ml}$. D, Standard curve derived from absolute quantification of 10 -fold serially diluted DNA from spores of $B$. dothidea. RFU: relative fluorescence units. 


$$
10^{\left(\frac{49.937-y}{6.863}\right)}
$$

the numbers of containers A to E spores corresponding to each sample were $588.17,272.77,209.99,65.99$, and 38.107 , respectively.

Application of q-LAMP assays detecting $B$. dothidea in air samples. Using the established q-LAMP detection system, the amplification times of spore samples quantitatively added to the Melinex tape were $29.42,35.94$, and $43.48 \mathrm{~min}$. According to the calculation formula:

$$
10^{\left(\frac{49.937-y}{6.863}\right)}
$$

the numbers of spores corresponding to each sample were 976.11, 109.49, and 8.73, respectively. The q-LAMP detection results of spore number were consistent with those of artificial additions (Fig. 6).

Spore samples from Melinex tapes in the spore catcher located in forests in Taiyang Town, Lin' an District, Hangzhou City were quantified. It was found that the amplification times of samples 1 to 4 were $38.01,39.07,39.85$, and $40.42 \mathrm{~min}$. According to the calculation formula $10^{\left(\frac{49.937-y}{6.863}\right)}$

the numbers of spores corresponding to each sample were 54.70, $38.28,29.51$, and 24.38 , respectively, whereas sample 5 did not show any amplification reaction (Supplementary Fig. S3).

\section{Discussion}

This study focuses on the development, validation, and application of the q-LAMP detection system. It is very important to explore a stable and sensitive detection system for the detection and quantification of $B$. dothidea in trunk, water, and air samples. As a laboratory analysis and routine method, PCR is the most widely used. However, it not only requires a high level of instrumentation in the amplification stage, but also, it has a long reaction time. At the same time, the Taqman-based real-time PCR assay also has this shortcoming. Therefore, rapid, specific, and economic q-LAMP assays are absolutely a good choice for the detection of $B$. dothidea. LAMP is an innovative technique for gene amplification and a simple diagnostic tool for the early detection (Tomito et al. 2008).

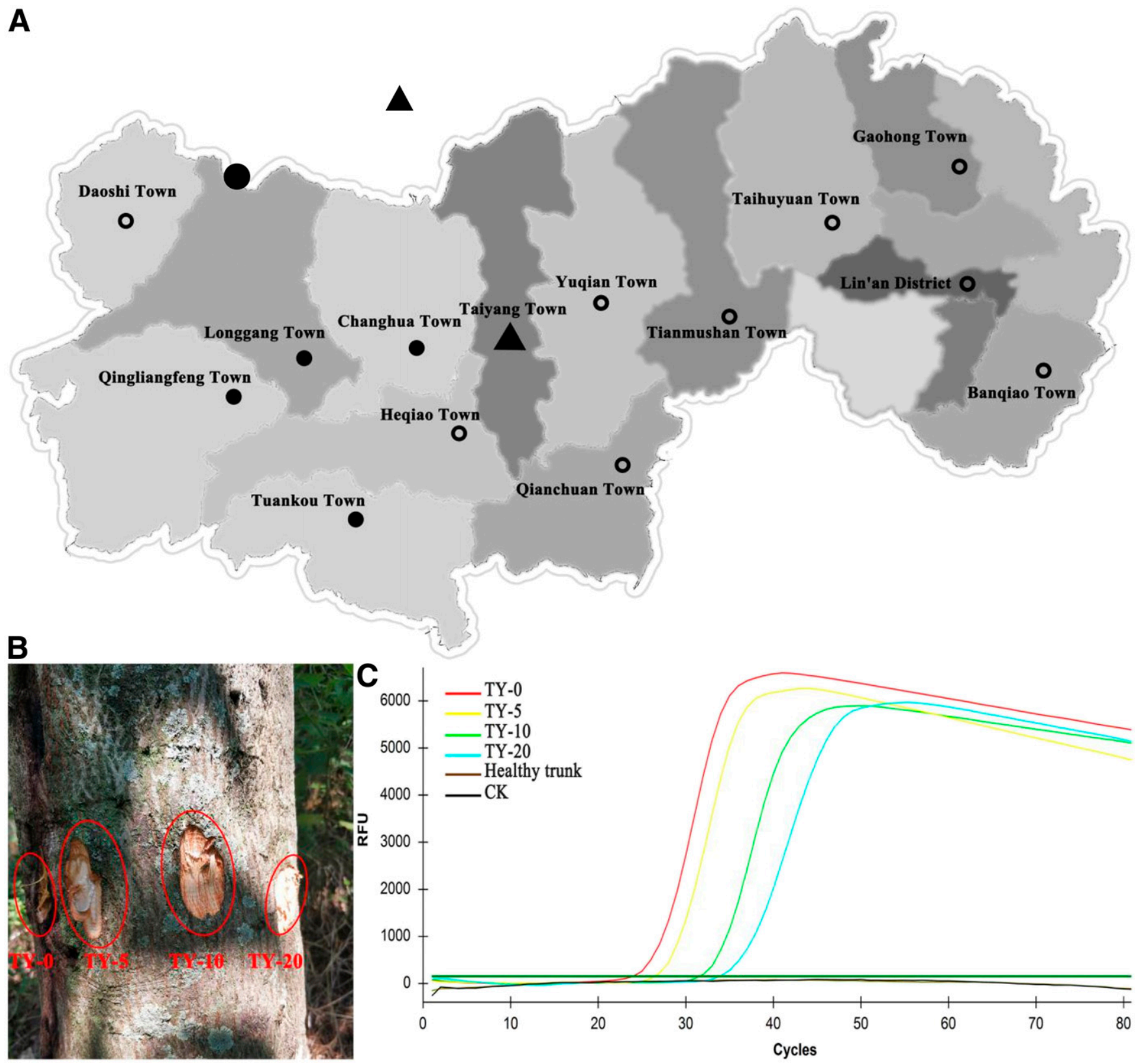

Fig. 4. The samples collected from the infected trunk for quantitative loop-mediated isothermal amplification assays. A, Location of sample collection points in Hangzhou City, China. B, Schematic diagram of sample collection on the trunk. C, A representative amplification plot of the sample from Taiyang Town. RFU: relative fluorescence units. 
To extract DNA from lesions more efficiently and quickly, three different methods were tried in this study: the improved CTAB method (Gao and Qiao-Ming 2008; Japelaghi et al. 2011), the commonly used SDS-CTAB binding method (Hua-Hui et al. 2010; Niu et al. 2010; Wei-Long et al. 2013), and the TIANGEN Plant Genomic DNA Kit (not shown in this article). Bark is thick and hard, and it is rich in polysaccharides, polyphenols, tannins, pigments, and other secondary metabolites. It has been found that the DNA separated by the simple CTAB method is brown because of polyphenol oxidation. Polysaccharides, tannins, and other substances combine with DNA to form a viscous gelatinous substance. The modified CTAB method and the commonly used SDS-CTAB binding method cannot prevent coprecipitation of the polysaccharide and the nucleic acid. The extracted genomic DNA has low purity and cannot be used to perform stable LAMP. However, using an FW100 high-rotation speed disintegrator to crush bark and then extract DNA according to the requirements of the TIANGEN Plant Genomic DNA Kit not only extracts high-quality samples but also, is time consuming. For the extraction of spore DNA from trunk canker fungus, to increase the sensitivity and sample size of the $B$. dothidea spores detection assay in water, a centrifugation-based method was used to concentrate the conidia in a smaller sample volume (Gehesquière et al. 2013). In addition, the combination of the Fsat-prep instrument and the TIANGEN Plant Genomic DNA Kit was used for the first time in this study to obtain

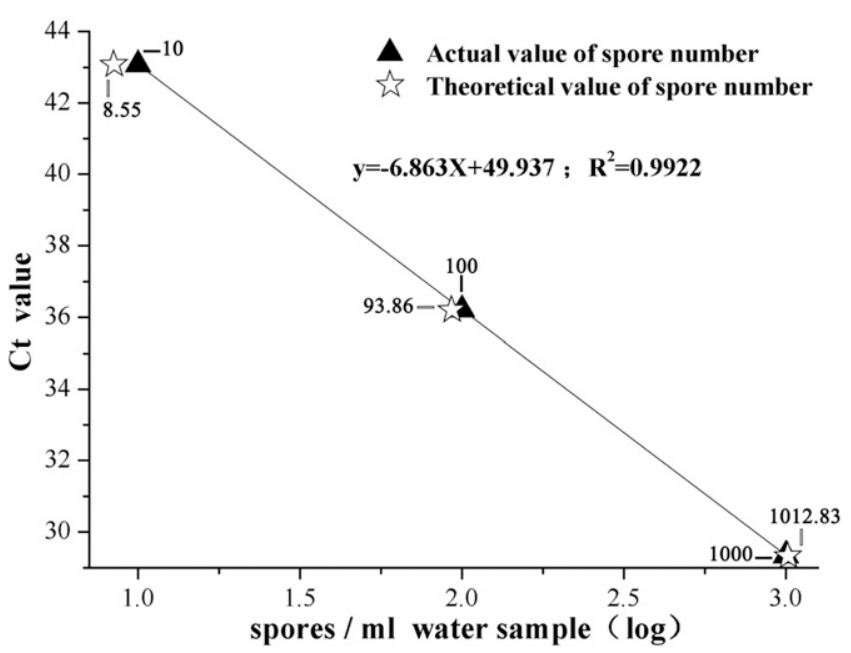

Fig. 5. Quantitative loop-mediated isothermal amplification assays detecting artificially added conidia in water samples. Ct: cycle threshold.

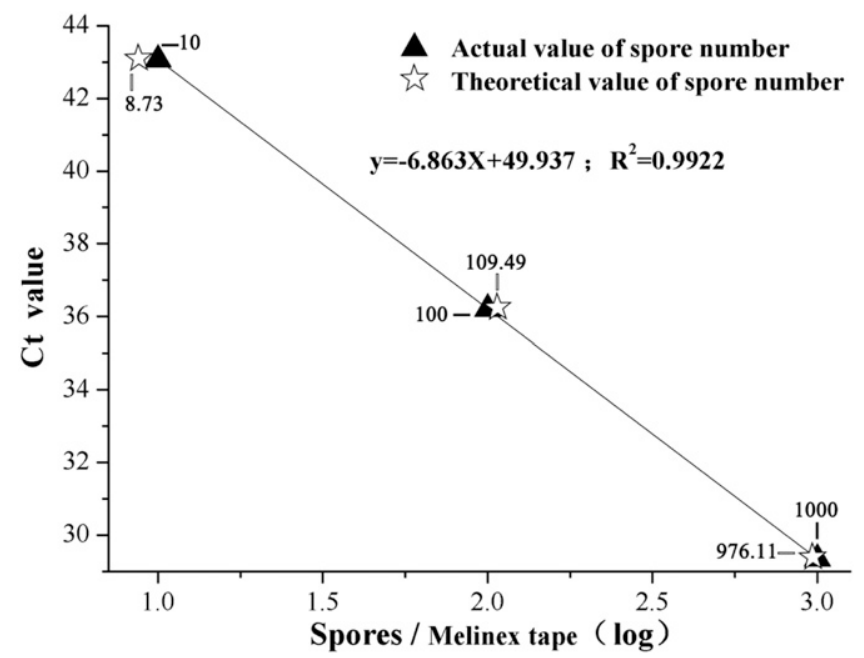

Fig. 6. Quantitative loop-mediated isothermal amplification assays detecting artificially added conidia in air samples. Ct: cycle threshold. high-purity spore DNA, which was of great help for subsequent LAMP detection.

Chinese hickory lives in a complex natural environment. There are not only $B$. dothidea but also, other endophytic fungi in the diseased trunk. Therefore, how to specifically detect $B$. dothidea in such an environment is very important for the occurrence and development of the disease. In this study, several endophytic fungi on Chinese hickory were isolated, and primers were successfully designed to specifically detect trunk canker fungus based on the difference in the area of $\beta$-tubulin.

Using the q-LAMP detection technology established in this study, samples with no symptoms on the trunk surface can be detected. In addition, the q-LAMP assay results of trunk canker fungus showed that, with the increase of the distance between the collection site and the visible lesions, the DNA quantity of the detected trunk canker fungus decreased continuously, but when the collection distance exceeded $20 \mathrm{~cm}$, the detection success rate was greatly reduced; of course, there was also the situation that the collection site was not infected by the trunk canker fungus. At present, the surgical removal of canker lesions is an important technique to control trunk canker disease on Chinese hickory (Yang et al. 2009). Our results indicated that $B$. dothidea existed not only in the canker lesions but also, in the tissues around them. Therefore, treatment of the trunk not limited to the lesions will be expected to have a better outcome. Trunk canker fungus has the characteristics of latent infection; in the absence of visible lesions, we cannot determine whether Chinese hickory trees have been infected by trunk canker fungus. In future research, it is still necessary to optimize and improve this technology to detect trunk canker fungus successfully and accurately before the appearance of visible lesions. However, this technology can monitor changes of spores in water and air, which is very important for the prediction and prevention of Chinese hickory trunk canker. Previous studies suggested that $B$. dothidea in a California pistachio orchard was a water splashdispersed pathogen with relatively short distances of spore dispersal (Ahimera et al. 2004; Michailides 1993). In additional studies, we will adopt this technique to monitor the changes of spores in water and air for successive years to analyze their correlations with the outbreak of trunk canker disease. This can give more information about the epidemiology and inoculum dispersal of $B$. dothidea infecting Chinese hickory.

\section{Acknowledgment}

We thank LetPub (https://www.letpub.com) for its linguistic assistance during the preparation of this manuscript.

\section{Literature Cited}

Ahimera, N., Gisler, S., Morgan, D. P., and Michailides, T. J. 2004. Effects of single-drop impactions and natural and simulated rains on the dispersal of Botryosphaeria dothidea conidia. Phytopathology 94:1189-1197.

Chotiwan, N., Brewster, C. D., Magalhaes, T., Weger-Lucarelli, J., Duggal, N. K., Rückert, C., Nguyen, C., Garcia Luna, S. M., Fauver, J. R., Andre, B., Gray, M., Black IV, W. C., Kading, R. C., Ebel, G. D., Kuan, G., Balmaseda, A., Jaenisch, T., Marques, E. T. A., Brault, A. C., Harris, E., Foy, B. D., Quackenbush, S. L., Perera, R., and Rovnak, J. 2017. Rapid and specific detection of Asian- and African-lineage Zika viruses. Sci. Transl. Med. 3. doi: 10.1126/scitranslmed.aag0538.

Dai, D. J., Wang, H. D., Wang, Y. P., and Zhang, C. Q. 2017. Management of Chinese hickory (Carya cathayensis) trunk canker through effective fungicide application programs and baseline sensitivity of Botryosphaeria dothidea to trifloxystrobin. Australas. Plant Pathol. 46:75-82.

Gao, J., and Qiao-Ming, L. I. 2008. The DNA extracting and SSR primer screening of Acacia pennata (Leguminosae). Acta Bot. Yunnanica 30:64.

Gehesquière, B., D’Haeyer, S. T. K., Pham, K. J., Van Kuik, A., Maes, M., Höfte, M., and Heungens, K. 2013. qPCR assays for the detection of Cylindrocladium buxicola in plant, water, and air samples. Plant Dis. 97:1082-1090.

Hua-Hui, Y. U., Yang, Z. L., Yang, X., Shu, X., and Liu, R. N. 2010. Effect of different methods on endangered plant Magnolia officinalis DNA extraction from leaves. J. Cent. S. Univ. For. Technol. 30:45-49.

Japelaghi, R. H., Haddad, R., and Garoosi, G. A. 2011. Rapid and efficient isolation of high quality nucleic acids from plant tissues rich in polyphenols and polysaccharides. Mol. Biotechnol. 49:129-137.

Jiliang, C., Huang, X., Wu, A., Zhou, S., Huang, D., and Jinping, L. 2011. An efficient extraction method of pathogenic fungus DNA for PCR. Mycosystema 30:147-149.

Lisboa, D., Silva, M., Machado, A., Pinho, D. S., Borges, L., Pereira, O., and Furtado, G. 2016. First report of botryosphaeriaceous fungi causing canker 
on Cedrela fissilis and leaf spots on Cariniana estrellensis in forest nursery in Brazil. For. Pathol. 46:362-365.

Ma, L. J., Lin, J. Y., Li, Q., Zhang, L. Q., and Chen, A. L. 2009. Antifungal constituents from the husk of Carya cathayensis. Sci. Silvae Sin. 45:90-94.

Marsberg, A., Kemler, M., Jami, F., Nagel, J. H., Postma-Smidt, A., Naidoo, S., Wingfield, M. J., Crous, P. W., Spatafora, J. W., and Hesse, C. N. 2017. Botryosphaeria dothidea: A latent pathogen of global importance to woody plant health. Mol. Plant Pathol. 18:477-488.

Michailides, T. J. 1993. Spore release by Botryosphaeria dothidea in pistachio orchards and disease control by altering the trajectory angle of sprinklers. Phytopathology 83:145-152.

Niu, C., Kebede, H. L., Auld, D., Woodward, J., Burow, G., and Wright, R. 2010. A safe inexpensive method to isolate high quality plant and fungal DNA in an open laboratory environment. Afr. J. Biotechnol. 7:2818-2822.

Phillips, A. J. L. 2002. Botryosphaeria species associated with diseases of grapevines in Portugal. Phytopathol. Mediterr. 41:3-18.

Slippers, B., Smit, W. A., Crous, P. W., Coutinho, T. A., Wingfield, B. D., and Wingfield, M. J. 2007. Taxonomy, phylogeny and identification of Botryosphaeriaceae associated with pome and stone fruit trees in South Africa and other regions of the world. Plant Pathol. 56:128-139.

Tomito, N., Mori, Y., Kanda, H., and Notomi, T. 2008. Loop-mediated isothermal amplification (LAMP) of gene sequences and simple visual detection of products. Nat. Protoc. 3:877-882.

Úrbez-Torres, J. R., Leavitt, G. M., Voegel, T. M., and Gubler, W. D. 2006. Identification and distribution of Botryosphaeria spp. associated with grapevine cankers in California. Plant Dis. 90:1490-1503.
Wang, C. L. 2004. Study on anti-tumor of Juglaas mandshurica. Food Sci. 25: 285-287.

Wei-Long, H. E., Yang, L. H., Wang, X. F., and Lin, N. Q. 2013. Efficient DNA extraction from endosperm of Pinus massoniana and SSR-PCR system optimization. China For. Sci. Technol. 27:15-18.

Yang, S., Ding, L., Lou, J., Zhang, Q., Wu, J., and Hu, G. 2009. Occurrence regularity of Carya cathayensis canker disease and its control. J. Zhejiang For. Coll. 26:228-232.

Yunwei, J. U., Zhao, P., Huang, L., Cao, X., Liang, Y., Jian, Y. E., and Gao, J. 2015. Analysis of Carya illinoensis main diseases occurrence and control. J. Nanjing For. Univ. 39:31-36.

Zhang, C. Q., Liu, Y. H., and Xu, B. C. 2015. First report of Fusarium root rot on Chinese hickory (Carya cathayensis) caused by Fusarium oxysporum in China. Plant Dis. 99:1284.

Zhang, C. Q., and Xu, B. C. 2011. First report of canker on pecan (Carya cathayensis) caused by Botryosphaeria dothidea in China. Plant Dis. 95:1319.

Zhang, M., Lin, M., Cao, X., Zhao, S., Jiang, D., Wang, B., Wang, S., Fan, Y. Guo, M., and Lin, H. 2018. Difference in $\mathrm{pH}$ value and nutrient and bacterial diversity in the Carya cathayensis forest soil under different management models. Biodiv Sci 26:611-619.

Zhu, C., Deng, X., and Shi, F. 2008. Evaluation of the antioxidant activity of Chinese hickory (Carya cathayensis) kernel ethanol extraction. Afr. J. Biotechnol. 7:2169-2173.

Zhu, Z., Shi, H., Lei, F., and Zhang, C. 2016. Quantifying Botryosphaeria dothidea infection causing canker disease on Carya cathayensis using realtime PCR. J. Zhejiang A \& F Univ. 33:364-368. 